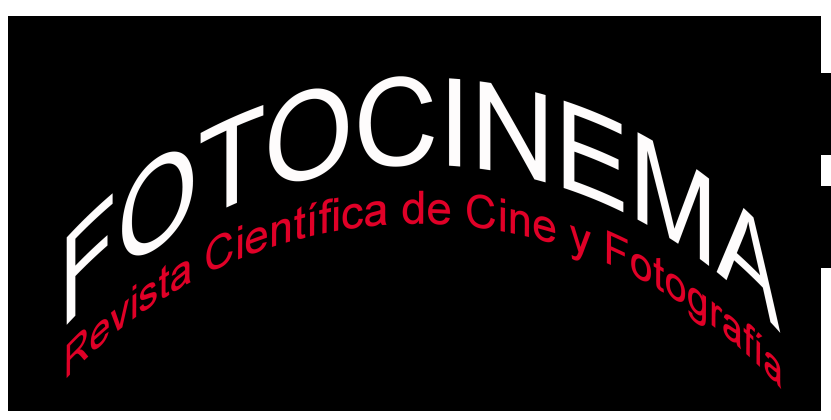

\title{
NARRATOLOGÍA PORNO. UNA LECTURA SEMIÓTICA DE TRAS LA
} PUERTA VERDE

\section{PORN NARRATOLOGY. A SEMIOTIC READING OF BEHIND THE GREEN DOOR}

\author{
Álex Mendíbil Blanco, Francisco García García y \\ Ma Luisa García Guardia \\ Universidad Complutense de Madrid, España \\ alexmendibil@gmail.com
}

\section{Resumen:}

La narrativa del cine pornográfico ha sido objeto de muchas polémicas y en algunos casos de estudio, pero asumiendo generalmente que el argumento o trama del film era el contenedor de todo el relato, subestimando la narratividad de la esencia propia del porno: las escenas de sexo explícito. En los textos pornográficos el argumento no suele ser un fin en sí mismo, sino una herramienta de carácter más o menos funcional, o incluso paródico, y son las escenas de sexo las que constituyen el núcleo del relato, tan narrativas como una escena de baile en un musical. El porno actual hace tiempo que dejó de ser "cine" y prescinde cada vez más del argumento convencional, por lo que planteamos esta base teórica que prioriza la forma sobre el contenido, y propone herramientas que sirvan para analizar la narrativa de las escenas sexuales explícitas de un largometraje o de un video breve de Internet.

\begin{abstract}
:
The narrative of film pornography has been the subject of many controversies and in some cases academic studies, but generally assuming that the plot of the film was the container of the whole story, underestimating the narrative capabilities of the true essence of porn: the scenes of explicit sex. Usually, in the pornography text the plot is not a goal unto itself, but a tool more or less functional, or even the subject of a parody, and it is the sex scenes that constitute the nucleus of the narrative, as a dance number in a musical. The current pornography has long ceased to be "cinema" and it increasingly ignores the conventional plot, so we propose this theoretical basis that prioritizes form and structure over plot, and proposes tools that help us to analyze the narrative of explicit sexual scenes either of a feature film or a brief video of Internet.
\end{abstract}

\section{Palabras clave:}

Cine pornográfico; narrativa; semiótica; guion; discurso.

\section{Keywords:}

Film pornography; narrative; semiotics; script; discourse. 
Cómo citar: Mendíbil Blanco, A., García García, F. y García Guardia, M. L. (2017). "Narratología porno. Una lectura semiótica de Tras la puerta verde". Fotocinema. Revista científica de cine y fotografía, $\mathrm{n}^{\mathrm{o}} \mathrm{XX}$, pp. 155-177. Disponible: http://www.revistafotocinema.com/

\section{Introducción}

La producción y distribución de cine pornográfico ha experimentado cambios drásticos durante los últimos quince años, provocados por la expansión de la tecnología digital y de Internet, hasta el punto de que el propio término "cine porno" ha quedado obsoleto. Si bien el formato de soporte y exhibición dejó de ser "cine", entendido como el celuloide o material fotoquímico, allá por los primeros años ochenta (Schaefer, 2002, p. 4), hoy en día tampoco resulta pertinente la acepción de cine como largometraje, ya que el mercado ha volcado su atención en Internet a través de la adquisición de cortos o mediometrajes por streaming. La progresiva e imparable adaptación a estas variables de orden tecnológico y mercadotécnico ha afectado de manera evidente y drástica a la narrativa del género, como ya afectaron los primeros cambios de película (Schaefer, 2002; Williams, 1989, p. 119), llegando actualmente a la paradoja de que lo que tradicionalmente se ha considerado "cine porno", es decir la etapa de exhibición legal cinematográfica y videográfica de largometrajes entre los años 70 y los 80 principalmente, se podría considerar ya una excepción, una anomalía en la historia de la producción audiovisual pornográfica. Al considerar la narración de una película pornográfica de las que hoy se consideran clásicos, por ejemplo Garganta profunda (Deep Throat, Gerard Damiano, 1972), históricamente se ha prestado atención esencial al relato del film, en el sentido de "fábula" o "historia" definidos respectivamente por Todorov (1970, p. 157) o Chatman (1990, p. 45). Es decir los argumentos visibles, los acontecimientos que se nos presentan a través de unos personajes y unas acciones que suceden de forma correlativa, encadenante y vinculante. Exactamente igual, por tanto, 
que el análisis narrativo de una película no pornográfica. Existen definiciones que, incidiendo en esta aproximación, aluden a lo pornográfico de estos films como "interrupciones" en la narración del relato, cuando son precisamente estos segmentos lo que dan entidad de pornografía a una película. En cambio, lo primero que se percibe en el caso del porno anterior a la legalización, normalización y comercialización de largometrajes (los llamados stag films, o loops), y también en el porno posterior para Internet, es que esa historia, ese relato de personajes y sucesos dramatizados, es reducido a la mínima expresión, cuando no eliminado por completo. A simple vista, lo que permanece inalterable en toda forma de pornografía que conocemos es eso que algunos han llamado "interrupción", y otros en un sentido más pragmático y explícito, the money shot o the medical shot (Ziplow, 1977), es decir los primeros planos de genitales en acción e interacción. Sin embargo, su capacidad narrativa, sea la que fuere, apenas se tiene en cuenta a la hora de analizar la obra desde una perspectiva narratológica. Por otro lado, en esta clase de textos donde fuerzas como el placer, los cuerpos, las identidades de género, y las relaciones de poder entre ellas juegan un papel tan determinante (Foucault, 1977), la interpretación de las variables narrativas que encierran los argumentos visibles ha ido transformándose radicalmente en los últimos años, sujeta a la influencia de corrientes de pensamiento como el feminismo, el post-feminismo y las teorías queer, que lógicamente han mostrado interés en esta popular representación de la sexualidad. Cabe preguntarse si esos enfoques dependen en mayor o menor medida del análisis de las estructuras narrativas más relevantes o si, por el contrario, se podría ahondar en el núcleo narrativo del porno observando capas menos periféricas y funcionales. Este estudio propone por ello una lectura que privilegie el análisis narrativo de las escenas pornográficas sobre las no pornográficas, y que pudiera ser trasversal e inclusivo, aplicable a cualquier época y formato de pornografía ya sea cine, video, escena, o retransmisión desde una webcam. 


\subsection{Contexto histórico}

Cuentan los cinéfilos que el director Josef von Sternberg imaginaba sus películas con Marlene Dietrich proyectadas al revés, para que el público no se fijara en la historia o el guion, sino en el estilo visual, en el juego de luces y sombras. Que sea o no una anécdota apócrifa es lo de menos, lo característico es que ya a principios de los años 30 cabía pensar que a la hora de representar en el cine las voluptuosidades de la razón y el cuerpo, en este caso de un icono clásico del erotismo como la Dietrich, era recomendable prescindir de la lógica y la linealidad de un argumento convencional. Mientras tanto, en los circuitos subterráneos, se rodaban y se distribuían stag films, cortometrajes pornográficos que existían desde los inicios del cine, y habían alcanzado su edad dorada en los años 20 (Di Lauro y Rabkin, 1976, p. 53). Los stag films eran pequeñas películas donde un grupo pequeño de personas practicaban sexo ante la cámara, sin apenas necesidad de situación dramática; a lo sumo algún disfraz para esbozar un personaje y un planteamiento elemental, similar al de un chiste o un gag, aunque con el tiempo evolucionaron a tramas más enredadas y distintos géneros. Al margen de que existiera un mercado o una audiencia más o menos consolidada, según la situación política y cultural de cada país, estos cortometrajes eróticos o pornográficos brotaron allá donde había una cámara, con similares características formales y de contenido.

Fue fundamentalmente el avance tecnológico en materia de cámaras y películas, junto a la apertura legislativa en cuanto a su exhibición, lo que poco a poco obligó a los creadores de cine pornográfico a incorporar argumentos y personajes "de ficción" mejor construidos, para ajustarse a las duraciones de entre sesenta y noventa minutos y competir en el mercado cinematográfico estándar (Schaefer, 2002, p. 12). No solo era una cuestión de rellenar metraje, según la ley estadounidense por ejemplo, la película pornográfica conseguía permiso para estrenarse si demostraba un mínimo "interés general o artístico", una ambigüedad legal que se aplicaba con mucha laxitud. Podemos concluir que, por lo general, el recurso del argumento y los personajes en el cine porno fue más una necesidad de orden 
técnico y político que una aspiración natural del género, aunque obviamente se han dado casos excepcionales. Es en este contexto donde claramente se disocian dos elementos del relato que antes discurrían de forma cohesiva: las escenas que recrean una ficción en sentido tradicional, y las escenas explícitamente pornográficas, o de "no ficción", como veremos más adelante. Esta división volvió a alterarse con la aparición del video, que provocó un abaratamiento de costes y una pérdida de calidad visual y, en consecuencia, de ambición narrativa (Kleinhans, 2006). Sin embargo, cuando la competencia se dispara años más tarde y la tecnología remonta, el escenario se modifica una vez más. A finales de los 90 se empezaron a ver tímidos avances de insertos pornográficos en el cine de autor (Los idiotas, Idioterne, Lars von Trier, 1998; Romance, Catherine Breillat, 1999; O Fantasma, João Pedro Rodriges, 2000, entre otras), peculiaridad que se mantiene viva gracias a los festivales de cine, pero fue una propuesta de orden estético (algunos apuntan que inspirada por el Movimiento Dogma de Lars Von Trier, al que pertenece Los idiotas), y de nuevo con decisivo impacto en la producción al permitir abaratamiento y simplicidad, la que volvería a enterrar las intenciones narrativas del género. Nos referimos al porno gonzo y al "porno amateur", estilos que persiguen mayor verosimilitud e intensidad mediante el uso de técnicas documentales y prescindiendo de toda artificiosidad dramática, haciendo partícipe a la cámara de la diégesis del relato. En la actualidad, el llamado post-porno o el porno queer están en primer lugar ampliando las subjetividades reconocidas por la pornografía, y en segundo, transformando las pantallas:

La pospornografía no será sino el nombre de las diferentes estrategias de crítica y de intervención en la representación que surgirán de la reacción de las revoluciones feminista, homosexuales y queer frente a estos tres regímenes pornográficos (el museístico, el urbano y el cinematográfico). (Preciado, 2008, p. 46).

Todo ello está contribuyendo a una vuelta al formato corto y sin necesidad de andamiaje argumental, comparable al cine autoproducido DIY del punk (García Castillo, 2011, p. 387). Sumando a estos cambios la expansión de 
Internet y la ampliación de la legalidad a la mayoría de países de Occidente y Latinoamérica, el porno está volviendo de forma espontánea a lo que parece su estado original y natural, esa suerte de stag film digital y accesible en la red, de duración breve y argumento ligero o nulo, dirigido esencialmente a la representación de actos e identidades sexuales cada vez más variadas (van Doorn, 2010).

\section{Historia y discurso porno: marco teórico}

"La historia es una convención y no existe a nivel de los acontecimientos mismos", decía Todorov, afirmación que en el caso del cine porno pocos se atreverán a discutir. Sabemos que el cine porno trabaja en términos generales con un material dramático muy elemental, sostenido con clichés y estereotipos que sean fácil y rápidamente reconocidos por el espectador, para conducirlo al segmento pornográfico en sí mismo, verdadero núcleo y desencadenante de la película. La premiada guionista de cine porno Raven Touchstone (Penny Antine) aclara el procedimiento habitual en una entrevista:

Generalmente, el director decide qué escenas de sexo quiere en su película. Hay normalmente cinco o seis escenas, dependiendo de qué compañía esté produciendo y su estrategia. En una película de gran presupuesto podemos tener una orgía con mucha gente, y muchas escenas múltiples: dos chicas/un chico, dos chicos/una chica, un cuarteto, etc. Un video de bajo presupuesto podría tener cuatro escenas de chico/chica, una de chica/chica y un solo (masturbación). Lo que él quiera. Yo tengo que construir una historia viable alrededor de esas combinaciones, es como unir un puzzle. (Rouner, 2014).

Podemos afirmar, sin temor a equivocarnos y siguiendo la narratología estructuralista, que si en el porno separamos un estrato de la historia o lo narrado, y un estrato del discurso o lo narrante, lo narrado adquiere un plano subordinado. "La imaginación pornográfica habita un universo incomparablemente económico, por muy repetitivos que sean los acontecimientos que ocurren en él” (Sontag, 1985, p. 76). Ante una situación similar de aparente precariedad temática, y hasta de "reprobación moral" por 
su contenido, Roland Barthes alegaba que a la literatura del Marqués de Sade no se debía acceder por el universo de la historia, sino por el universo del discurso:

En cada página de su obra, Sade nos da pruebas de 'irrealidad' concertada: lo que ocurre en una novela de Sade es claramente fabuloso, es decir, imposible, o más exactamente, las imposibilidades del referente se transforman en posibilidades del discurso. (1997, p. 48).

Huelga decir que no se pretende derivar de esta relación que el cine pornográfico es equivalente a la literatura del Marqués, menos aún atendiendo al discurso, a pesar de que Susan Sontag escribe que:

Sade parece representar mejor los principales convencionalismos de la ficción pornográfica. En la medida en que la imaginación pornográfica tienda a convertir a una persona en intercambiable con otra y a todas las personas intercambiables con objetos. (Sontag, 1985, p. 63).

Lo que sí creemos propicio es transferir esa lectura estructural que hace Barthes de Sade al género pornográfico, que no parece tener entre sus prioridades representar una realidad, sino establecer un pacto con el destinatario, una convención más o menos básica, que le permita prestar atención a la forma específica en la que se cuenta, el discurso. El porno es, ante todo, discurso: una película porno que se contara en planos generales, o mediante elipsis, sin detenerse en la representación del acto sexual, dejaría de considerarse pornográfica. Para Barthes, Sade se sitúa entonces más cerca de la semiosis que de la mímesis, y como tal debe ser leído, desde el punto de vista del sentido y no del referente. Otro aspecto de la literatura sadiana llama la atención de Barthes, y resulta igualmente transferible al cine pornográfico, es lo que él llama el "lenguaje de la crudeza", refiriéndose a la vulgarización del léxico empleado, la constante y acumulativa recurrencia a figuras grotescas y transgresoras, y la propia subversión de la palabra o la sintaxis. Estrategias que el cine pornográfico ha acogido como propias, abandonando no solo el decoro de sus imágenes, sino la propia elegancia de la sintaxis cinematográfica, sirviéndose de zooms, primerísimos primeros planos, montajes redundantes y cualquier tipo de maniobra visual que 
incremente el impacto de las imágenes, sin preocuparse de la estética normativa que dicta el cine convencional. Este lenguaje crudo y vulgar es indicativo, según Barthes, de que la lectura que el autor propone es una lectura al margen del sentido, al margen de lo que narra la historia.

A esta línea se adscribieron muchos otros al estudiar las capacidades narrativas del cine porno, haciendo siempre hincapié en dos asuntos fundamentales: la huida de la realidad, y la extrema codificación del lenguaje pornográfico, es decir de la sintaxis cinematográfica (Gubern, 1989, pp. 1213). Linda Williams fue más allá en su fundamental estudio sobre el cine porno Hard Core (1989), notable por introducir las perspectivas de Foucault sobre sexualidad y poder, y por desligarse, en clave post-feminista, del rechazo unilateral contra el género, ilustrando su posicionamiento con una comparación tan elocuente que se ha convertido en referencial: el cine porno funciona narrativamente como el cine musical (Williams, 1989, p. 124), alternando episodios de narración clásica con una función representativa (la historia), con episodios donde momentáneamente se suspende esa representatividad en busca de una sublimación formal (los números musicales). Generalmente, el "número porno", como el número musical, tiende además a acompañar los finales de las escenas, a modo de resolución del conflicto o expresión de una emoción. Añade Williams en última instancia que, a pesar de que la sintaxis preconcebida del porno suprime gran parte de su carga significativa, no debe inferirse que el porno no tiene significado (1989, p. 183), o que tiene un significado neutro, sino que el significado se hace posible por otros medios, e incluso porque ciertos significados son suprimidos. Otra autora, esta vez desde una postura feminista anterior más crítica con la mirada falocentrista y opresora del cine, ya no pornográfico, sino convencional: Laura Mulvey, admite en su seminal artículo de 1975 "Visual Pleasure an Narrative Cinema” que la fragmentación del cuerpo mediante primeros planos destruye la ilusión del espacio renacentista (2001, p. 371), y así la mirada del espectador se distancia, rompiendo la verosimilitud y abriendo una fisura en la narración. Es decir, que la sintaxis del cine, mediante esos planos cortos y montajes 
fragmentados, oscurece o diluye en buena parte el significado, lo que sigue en consonancia con nuestra tesis de subordinar la historia al discurso del porno.

Volviendo a Barthes, mantenemos que ni siquiera en los segmentos pornográficos hay exactamente una función mimética del relato, ya que la imitación es algo contingente, no específico (1970, p. 43). Al cine porno, como relato, habría que atribuirle la categoría de relato funcional, en terminología de Propp y Barthes, ya que se encuentra fuertemente codificado tanto en el aspecto de la historia (las situaciones y personajes estereotípicos) como en el del discurso (el encuadre, el montaje, la frecuencia). Partiendo de lo más general, de esta división macroestructural entre escenas de ficción y escenas sexuales, podíamos distinguir que en los segmentos pornográficos subyace claramente una función cardinal o nuclear, puesto que como hemos visto constituyen el "nudo" del relato; mientras que las escenas ficcionadas o dramáticas adquieren una función catalítica, complementadora del núcleo mediante indicios e informantes.

\subsection{Herramientas para una lectura alternativa}

Podríamos pensar que en el caso de las escenas de sexo explícito entran en juego las estrategias discursivas del cine documental, más que las del cine de ficción. Así lo han visto autores tan dispares como Andre Bazin, Roman Gubern, o Bill Nichols, que incluso habla de una cualidad "etnográfica” de la pornografía, ya que responde a cuestiones sobre cómo se empieza el sexo, cómo acaba, dónde ocurre, con quién, cómo son los actores y actantes sexuales y "especialmente cómo es el acto sexual cuando se representa delante de una cámara" (Nichols, 1991, p. 211). Pero en esta última frase está la clave para tomar cierta distancia de estas posturas, ya que en el cine porno el sexo tiene poco de natural y espontáneo, sino que se representa solo y exclusivamente para la cámara, para que ésta lo registre con claridad, con todos los condicionantes diegéticos y extradiegéticos que ello conlleva. Por ello nos parece más acertada la expresión "ilusión de documental" que utiliza Escoffier (2007, p. 65), porque efectivamente el factor de realidad es esencial en el cine porno, en concreto en los segmentos de sexo explícito, pero basta con la ilusión de que lo que ocurre ante las cámaras es real. Sin embargo, 
conviene añadir que también este punto ha sido rebatido con rotundidad por filósofos como Baudrillard, que asegura que:

El único fantasma en juego en el porno, si es que hay uno, no es el del sexo, sino el de lo real, y su absorción, absorción en otra cosa distinta de lo real, en lo hiperrreal. El voyeurismo del porno no es un voyeurismo sexual, sino un voyeurismo de la representación y de su pérdida, un vértigo de pérdida de la escena y de irrupción de lo obsceno. (Baudrillard, 1981, p. 33).

De la misma manera piensa Willemen, para quien:

La espeficidad del género requiere un número máximo de imágenes explícitas, las cuales necesariamente fragmentan la narrativa, produciendo repeticiones constantes y haciendo virtualmente imposible el suspense o una sensación elemental de verosimilitud. (1992, p. 177).

Es entonces cuando la idea de que las escenas de sexo podrían funcionar como números musicales suena más propicia que el enfoque documental. Williams reconoce que, si bien ha habido intentos de estudiar las estrategias narrativas del número musical, nadie se ha atrevido con la forma de narrar de los segmentos de sexo explícito del cine porno, a los que acabamos de dar categoría de núcleo del relato pornográfico. No obstante, se han dado los primeros pasos, como consensuar una tipología general de escenas de sexo dentro del cine porno, y quizá un orden y una frecuencia, pero no mucho más allá. Varios autores señalan citan la misma fuente, el catálogo de tipos principales de escenas de Ziplow de 1977, que dentro de lo que podríamos denominar "porno ortodoxo" sigue vigente, a saber: masturbación, sexo heterosexual, lesbianismo, sexo oral, ménage à trois, orgías y sexo anal, a las que Williams añade en 1989 las escenas de sadomasoquismo (“sadie-max”). Se dejan fuera el sexo homosexual masculino por considerarse un tabú dentro del porno mainstream, sin olvidar que la ausencia del mismo es tan significativa o más que su presencia, objetivamente anecdótica. Esta catalogación, si bien es útil en cuanto a su constancia en el tiempo y su amplio alcance, se nos queda corta para avanzar en términos narrativos. Algunos se han aventurado a establecer un orden canónico de dichas escenas, que empezaría por la masturbación, seguido del sexo oral, el sexo 
heterosexual, a continuacion el segmento lésbico, y finalizando con un trío o una orgía, pero sin ir más allá del dato estadístico, que tampoco parece muy riguroso. Williams optó por definir tres fases de representación más generales pero narrativamente más instructivas: (1) la exhibición de partes del cuerpo normalmente ocultas, que provoca fascinación; (2) una representación más narrativa del "evento genital”, o acto sexual tipificado en lo que antes llamábamos "medical shot"; y (3) la escalada según un principio de máxima visibilidad del orgasmo masculino mediante la eyaculacion, el money shot. Es sencillo extrapolar de estas tres fases una vocación dramática clásica, aristotélica, en el sentido lineal y cronológico de la fórmula planteamiento-nudo-desenlace. De aquí arranca el tópico de que asociar la fascinación con el descubrimiento del cuerpo femenino y el desenlace con el orgasmo masculino convierte a la mujer en objeto representado y al hombre en sujeto de la representación (Mulvey, 2001). Pero Williams, entre otros, toma conciencia del problema de la visibilidad del placer femenino, que de ninguna manera se excluye del esquema narrativo sino que es parte esencial, si bien no protagoniza la catarsis final, ni tampoco ostenta una exaltación visual específica, como sí ocurre con la eyaculación masculina, que debido a su expresa fisicidad, es celebrada y subrayada con todo tipo de artificios cinematográficos (primeros planos, ralentís, repeticiones, encuadres múltiples). El placer femenino ciertamente se representa, en la práctica totalidad de los casos, mediante indicios o informantes visuales (plano del rostro o las manos) y sonoros (gemidos, diálogos), pero no podemos decir que ocupa una función catalítica en la sintaxis de la secuencia, sino más bien nuclear. Resulta anómalo encontrar una escena de sexo en el porno donde el personaje femenino exprese indiferencia o hastío, y si ese fuera el caso habría que dilucidar si la escena tiene una función diferente a la normativa, que es conjugar el placer por el sexo. Paradójicamente, en el cine erótico o softcore, aquel que recrea un acto sexual simulado, sin planos explícitos genitales, sí es habitual encontrar personajes femeninos a los que se les impide el placer sexual, ya sea por hastío o por violencia no consentida (una violación), temas que en el cine porno permanecen generalmente vetados. Williams concede 
además al cine porno posterior a los stag films, es decir a los largometrajes porno, una cierta "normalización” de la mujer deseante, la que disfruta y busca el sexo sin tapujos, personaje que en los primitivos stag films aparecía pasivo e incluso castigado (1989, p. 165).

Volviendo a las funciones de cada una de las unidades que componen la secuencia sexual, Williams se aventura en su comparación con el musical y sugiere que cada "número porno" soporta una función en el relato similar a la de los números musicales, que completan o ilustran partes del argumento del film. Siguiendo su analogía, las secuencias de masturbación individual serían como un "solo de baile" que expresa autosatisfacción, autoafirmación y disfrute; el sexo oral expresa deseo por el otro, excitación y anuncia destreza en el acto sexual, como un duelo de claqué entre dos bailarines; las de sexo en pareja expresarían cooperación y entrega mutua, en pos de la unión en uno solo; las escenas de tríos demuestran complicidad, coordinación, alternancia del liderazgo y enardecimiento del deseo; las de orgías manifiestan diversión, renuncia al liderazgo y embriaguez del deseo; y las de sexo anal podrían interpretarse con un juego de poder/sumisión que conduce al placer mediante la profanación de la norma. Sería necesario comprobar en cada caso que estas asociaciones encajan con el objetivo del relato, porque obviamente no son inamovibles, pero sí marcan la tendencia más frecuente. En cierta forma, estos comportamientos están dirigidos por los mismos escenarios culturales que invocan los llamados sexual scripts (guías o guiones sexuales) de la teoría sociológica de Simon y Gagnon (1986), que identifican patrones sociales aprendidos que organizan y excitan la imaginación de nuestras conductas sexuales. Esos sexual scripts se utilizan consciente e inconscientemente por los propios creadores de porno, desde el director a las actrices y actores, o a la persona particular que se graba con una webcam, representando en mayor o menor medida una fantasía sexual colectiva. Si tenemos en cuenta que las escenas explícitas de sexo son la parte menos detallada en el guion escrito de la película o el sketch, ya que se deja en manos de la pericia y la improvisación de los participantes y del director, 
si lo hay, más influencia le debemos reconocer a estos sexual scripts, y más atención a la hora de evaluar la narrativa del porno.

Recopilando, hemos propuesto una serie de herramientas que nos parecen definitorias de la narratividad de la escena sexual pornográfica: tipologías, grados y fases de representación, y subordinación a un relato propio y a un relato colectivo de orden sociológico. No son indudablemente las únicas, ni está en nuestra intención registrarlas todas, el campo está abierto a muchos enfoques, semióticos, psicoanalíticos, cinematográficos o bien mixtos, como los conceptos de Deleuze (1984) de la imagen afecto, la imagen pulsión y la rostrificación que conlleva todo primer plano, que parecen ajustarse como una segunda piel a estas secuencias de rostros y cuerpos exaltados (patéticos) aislados del espacio. Procede entonces una descomposición casi plano a plano de las secuencias de sexo, identificando tanto su sexual script como la sintaxis funcional de cada unidad, su ordenación, duración, combinación y su frecuencia, para así poder articular una gramática, inspirada en la erotografía o porno-gramática que Barthes encontró en la literatura de Sade (1997, p. 151).

\section{Un caso práctico}

Hemos escogido para aplicar esta lectura alternativa Detrás de la puerta verde (Behind the Green Door, Artie y James Mitchell, 1972), un título clásico del cine porno, de ese periodo anómalo de largometrajes con argumento, por diversas razones. La primordial, su interés en contar una trama con una carga ideológica evidente. Con ello podremos contrastar si lo que narra la trama y lo que narran las escenas de sexo es compatible. Una película gonzo o un clip de Internet sin argumento, sin historia en el sentido semiótico, no nos permitiría hacer una valoración tan clara, puesto que el contenido de la trama sería menor. Por otro lado, al ser una película tan popular, se ha escrito mucho y muy diferente sobre ella, desde que ayudó a romper tabús raciales, que fue el porno de la generación hippy, o que es profundamente misógina (Williams, 1989, p. 157), lo que también nos da la 
posibilidad de contrastar diferentes visiones. Confiamos que esta lectura menos restringida por la trama y más por las escenas sexuales, aporte luz en algún sentido. Para ello hemos procedido al visionado de la película, y al análisis pormenorizado de las escenas de sexo, anotando sus encuadres, su montaje, la ordenación, duración y frecuencia de los planos más significativos, la música o los efectos de sonido que le acompañan, y las funciones de representación que antes definimos.

La copia visionada tiene una duración de 71 minutos, fue rodada en $16 \mathrm{~mm}$ en in formato de 1.37:1, en color y con sonido monoaural. Las escenas sexuales explícitas ocupan aproximadamente 47 minutos, dejando por tanto unos 24 minutos para las escenas dramáticas. La película presenta a dos amigos adultos (George S. McDonald y Yank Levine), clase media trabajadora, que hablan en una cafetería de carretera sobre un lugar muy especial con una puerta verde, dando pie a un flashback que contiene prácticamente el resto del film. Durante los títulos de crédito, observamos a una mujer joven blanca (Marilyn Chambers) conduciendo un coche descapotable. La mujer se hospeda en el mismo hotel que los dos amigos, y se cruzan en la terraza. Esa noche, dos hombres (los directores de la película) secuestran violentamente a la mujer y la meten en un coche. Posteriormente, la dejan en manos de una mujer con una túnica negra en una habitación de luz blanca, que tranquiliza a la protagonista con un masaje y asegurándole que no corre ningún peligro. Por otro lado, los dos amigos llegan al club privado, donde les hacen entrega de unos antifaces y les dan paso a un escenario con la puerta verde. Una voz en off informa a los asistentes al espectáculo que la mujer secuestrada no va a sufrir daño, que sólo ocupa "el papel de víctima” y será liberada a la mañana siguiente, sintiendo que ha sido "amada como nunca antes". Saliendo por la puerta verde, unas mujeres con túnicas negras acompañan a la protagonista al centro del escenario, donde la someten a caricias y besos por su cuerpo desnudo. La mujer comienza a mostrar placer, y también el variopinto público, hombres, mujeres, transexuales, de todas las edades y condiciones. Un hombre negro entra en el escenario y penetra a la mujer, llevándola al orgasmo. A continuación, tres hombres colgados en trapecios ofrecen sus 
penes erectos a la misma mujer, mientras otro la penetra desde el suelo. Al mismo tiempo, el público, incluyendo los dos amigos, se entrega a una orgía, sin importar sexo, raza o aspecto físico. La mujer del escenario lleva al orgasmo a los hombres, que eyaculan sobre su rostro. Finalmente, acaba el flashback en la misma cafetería del principio. El amigo joven se despide y sale conduciendo su camión, mientras parece recordar o imaginar una escena de sexo con la chica del escenario, hasta que juntos llegan al orgasmo. Hasta aquí la trama de Detrás de la puerta verde, que desarrolla temas como la desinhibición para alcanzar el placer, el amor libre de normas o prejuicios, el sexo como ritual para unos iniciados, y la heterogeneidad de los cuerpos como algo a celebrar.

La película contiene cinco números sexuales muy diferentes: el primero y más comedido es el del masaje a la secuestrada, a la que otra mujer acaricia suavemente sus muslos y un pecho; el segundo, más intenso y ya en el escenario, donde seis mujeres acarician, besan y practican cunnilingus a la protagonista, para luego dar paso al hombre negro que la penetra vaginalmente; tercero, los tres hombres del trapecio son masturbados y reciben sexo oral de la mujer, mientras otro la penetra desde abajo vaginalmente; esto provoca la orgía entre el público, que se puede considerar un cuarto número; finalmente, el quinto número muestra una escena de sexo heterosexual con felación, cunnilingus y penetración vaginal entre la chica del escenario y el joven que asistía al show. Tenemos por tanto dos escenas lésbicas, la segunda en grupo, una penetración interracial, un quinteto de cuatro hombres y una mujer, una orgía múltiple, y un dúo heterosexual ortodoxo. Pasaríamos así por varios sexual scripts, ternura y complicidad (números lésbicos), luego sumisión, transgresión y exotismo (hombre negro), entrega total al grupo, fusión de los cuerpos y éxtasis (quinteto y orgía), y para finalizar, un momento de intimidad y amor (sexo en pareja) que no queda claro si es algo que ocurrió o una ilusión, en todo caso ocurre en un espacio abstracto, o mental (transparencias, fondo negro). Las funciones de estos números acompañan por tanto la función del relato dramático, que como decíamos habla de desinhibición, amor libre y renuncia a los prejuicios, 
aunque la vuelta al final al sexo en pareja heterosexual clásica, contraviene esa progresión lógica, si bien su naturaleza ilusoria en la diégesis del relato permite otras interpretaciones, como veremos más adelante.

La configuración de los encuadres y el montaje hace distinguir al menos dos fases en cada número, una primera configuración de planos generales y medios con un ritmo de montaje clásico, y una segunda de planos muy cerrados, algunos casi abstractos por su cercanía, y un montaje más frenético. Ello subraya la idea de que el sexo, en todos los casos, nos permite abandonar poco a poco nuestros cuerpos y llegar al éxtasis. Esta idea se hace más presente que nunca durante el cuarteto y la orgía, donde literalmente los cuerpos se confunden, los rostros se disuelven, las zonas erógenas se rostrifican y el concepto del Cuerpo sin Órganos (CsO) de Deleuze y Guattari parece hacerse carne. Es sin duda el núcleo del film (algo más de 20 minutos), una apología del sexo entendido como fin de las diferencias, de los tabúes y del yo, que desobedece constantemente lo convencional, incluso con sentido del humor.

La orgía culmina en una escena que convierte el clásico money shot en una experiencia psicodélica, multiplicando las eyaculaciones sobre el rostro de Marilyn Chambers con toda clase de efectos de postproducción: ralentíes, imagen polarizada, filtros de colores, repeticiones... Convirtiendo la habitual sublimación de esta representación del placer masculino, en una catarsis lisérgica. Este tipo de imágenes y con este encuadre tan "patético" en el sentido Deleuziano, que idolatra el pene y profana el rostro sumiso de la mujer, se ha interpretado habitualmente como un desagravio por el complejo de castración freudiano, y es cierto que la película adquiere aquí su cénit, contradiciendo incluso planteamientos antes manifestados, tanto en las escenas sexuales como en las dramáticas. Extraer de esta secuencia de casi seis minutos la conclusión de que el placer de la mujer está supeditado a la eyaculación masculina, ante la que se postra como una sierva, es prácticamente inevitable. Pero conviene también matizar que otras eyaculaciones han sido suprimidas en el resto del film, notablemente en el número con el hombre negro y en el número "romántico" final, quizá no 
tanto por empoderar el placer femenino como por vigorizar a la secuencia central de las eyaculaciones. La contradicción es innegable, y de alguna manera el mensaje de amor libre e igualdad de sexos y cuerpos queda aquí comprometido, incluso atenuando su relevancia como una frivolidad estilística de los directores, que claramente están citando la secuencia psicodélica de 2001: Una odisea del espacio (2001: A Space Odissey, Stanley Kubrick, 1968). Este desliz estilístico, y su importancia en el cuerpo del film, no puede ser obviado en una lectura rigurosa de las escenas de sexo.

Más problemática es sin duda la representación del placer femenino, verdadero estigma del cine porno, que aquí se resuelve con no poca controversia. Lo interesante del caso es que la polémica se circunscribe a lo que hemos considerado la parte dramática del film y no tanto a las escenas sexuales explícitas, lo cual, como venimos manteniendo en este estudio, debería ser tomado en un sentido no literal, "al margen del sentido" como decía Barthes. La sinopsis antes detallada habla de una mujer secuestrada y sometida a todo tipo de prácticas sexuales contra su voluntad y ante un público oculto tras un antifaz; las acusaciones de misoginia de Williams no parecen infundadas. En términos puramente dramáticos, el argumento se protege -quizá a sabiendas- de estas acusaciones con pretextos solapados, como si la mujer hubiera pactado la experiencia ("She's here" avisa el conserje por teléfono cuando ella llega al hotel) y todo fuera parte de un juego. Sea como fuere, nos parecen clichés narrativos que se usan como parte de un sexual script preconcebido: la "fantasía" de la violación, perpetrada además en un escenario, y no como la representación de una lacra machista. Sin embargo, las escenas sexuales narran lo contrario, priorizando de manera notable el placer de la protagonista sobre el placer de cualquier otra persona, hombre o mujer, procurándole una visibilidad constante durante toda la película. Concretamente hemos contabilizado 16 minutos de planos (de los 47' totales de sexo) dedicados exclusivamente a mostrar el placer del personaje de Marilyn Chambers, esto es, primeros planos de su rostro aislado en actitud extática, de los cuales 7 pertenecen a escenas lésbicas. En cuanto a la cuestión de si, en esos 16 minutos, ella es objeto o sujeto del deseo, está 
abierta a la interpretación, aunque se aprecia que el personaje parte de una actitud pasiva y avanza hacia una postura de igualdad, o incluso liderazgo, de la iniciativa sexual. Tampoco podemos obviar que ése es su papel dentro del sexual script, la mujer apática que descubre poco a poco el placer del sexo, y que la fisonomía y caracterización de la actriz en ningún momento hacen gala de una feminidad artificial y sexista, propia de un icono sexual masculino. Todo lo contrario, se describe conscientemente un personaje de aspecto corriente, sin apenas maquillaje ni un físico opulento, diríase incluso, andrógino. Además, en la orgía concurren todo tipo de mujeres como se ha dicho, acordes a los cánones de belleza y también opuestas, femeninas y no femeninas, con innegable iniciativa sexual y búsqueda activa de su propio placer, ya sea consigo mismas, con otras mujeres, u otros hombres. A nadie pasa desapercibida la insistencia del film en evitar las apariencias y conductas sexuales estandarizadas, aspecto muy notorio en el imaginario pornográfico, aficionado como se sabe a promover estereotipos patriarcales.

Sería ingenuo afirmar que los hermanos Mitchell logran esquivar la mirada fetichista heteronormativa a la que Mulvey hizo referencia en su artículo, estamos hablando de cine porno de los primeros años 70, pero sí hay que reconocer que su cámara raramente busca la identificación con el hombre deseador, salvo unos pocos planos de mirada subjetiva masculina o de escorzo. El punto de vista es muy variopinto, imposible decir neutro, pero sí capaz de albergar miradas y sensibilidades femeninas, homosexuales, o queer. Incluso se puede decir que la presencia falo-céntrica y totémica del pene, como en la controvertida escena de las eyaculaciones, permite una visión homoerótica tan sustancial como la hetero-patriarcal. La aparición del hombre negro portador del gran falo, con toda la significación racista y sexista que contiene y se le ha reprochado, posee también un componente paródico y fantástico, otro sexual script en clave humorística, como evidencian esas mallas blancas que bordean el pene y el maquillaje carnavalesco, que lo convierten en un ser mitológico, mitad blanco mitad negro, de rostro femenino y poderoso falo. La ambigüedad, como vemos, sobrevuela toda la película de principio a fin. 
También de ambiguo se puede calificar el inesperado final, con esa declaración de amor heterosexual y convencional, que sueña o recuerda el camionero mientras conduce. Nos sorprende porque acabamos de asistir a la celebración de una orgía polisexual y extraordinaria, y el choque con la “normalidad” desconcierta. Pero ¿qué hacer después de la orgía? Se pregunta Baudrillard:

Ya sólo podemos simular la orgía y la liberación, fingir que seguimos acelerando en el mismo sentido, pero en realidad aceleramos en el vacío, porque todas las finalidades de la liberación quedan ya detrás de nosotros [...] ¿Qué hacer entonces? Es el estado de la simulación, aquel en que sólo podemos reestrenar todos los libretos porque ya han sido representados. (1993, p. 9)

Y eso exactamente es lo que parecen decirnos los Mitchell: la escena sexual entre el camionero y Marilyn Chambers no parece real, entra en escena mediante un fundido larguísimo que le da aspecto de quimera, flotando en un espacio vacío, negro, el de la memoria o la imaginación. Es además una escena mil veces representada, que concluye en la clásica posición del misionero, abrazados y sin eyaculación a la vista, quizá porque permanece dentro de ella, como una declaración de amor heterosexual y procreador. Acabar así una película porno tiene mucho de ironía y hasta de farsa, puntuada por esa música country tan poco sofisticada, y por ese barrido final del camión blanco que parece suplantar, en un plano metafórico nada sutil, la eyaculación ausente.

\section{Conclusiones}

La lectura del discurso de las escenas sexuales de la película Detrás de la puerta verde, en paralelo al contenido de su argumento y de sus escenas dramáticas, nos ha permitido entender y valorar de una forma más objetiva las opiniones que se han vertido sobre ella, así como la coherencia o el compromiso con su argumento "oficial” o visible. En el cómputo de las escenas de sexo se puede reconocer su interés en reivindicar una sexualidad más abierta y heterogénea que la habitual, dando lugar a un variado tipo de 
relaciones, identidades y estéticas sexuales. También se reconoce una apología del sexo en grupo, como una ceremonia consentida y placentera que si bien se realiza en círculos más o menos exclusivos, está al alcance de cualquier clase social y condición. Si bien la película da protagonismo a una mujer que tampoco destaca por ninguna característica social, física o económica, una mujer corriente que descubre también las virtudes de esta sexualidad libre, las escenas sexuales en las que ella participa tienden a limitar su papel al de sujeto pasivo, o sujeto del deseo, que nunca parece tomar la iniciativa. Aunque este rol encaja en principio con el personaje que interpreta, la mujer que ha de descubrir una realidad que desconoce, sí podemos apreciar que conforme avanza la película su rol evoluciona muy poco, siendo finalmente receptora sumisa de una serie de eyaculaciones masculinas que conforman el clímax. Esta escena, sin duda central en el relato del film, parece contradecir o traicionar el argumento antes planteado, haciendo hincapié en una sexualidad de tipo patriarcal donde el hombre desea y la mujer es objeto del deseo. Si bien esto es patente en la trama de la protagonista, el resto de escenas sexuales, que ocupan un espacio similar en el film, abogan por la sexualidad libre y desprejuiciada que parecen defender los directores, por lo que el discurso patriarcal deviene en un discurso más ambiguo y abierto a otras lecturas. Lo mismo ocurre con la trama del secuestro y la violación de la mujer protagonista, presentes en las escenas dramáticas del film, que deben ser relativizadas y no interpretadas en su literalidad, puesto que las escenas sexuales indican lo contrario, una insistencia en representar el placer de la mujer protagonista. De esta forma podríamos decir que el secuestro y la violación que plantea la trama es más bien un sexual script, una fantasía que no debe ser leída solo en un contexto de violencia de género o de explotación sexual. El discurso del film, y en concreto el de varias escenas sexuales, da pruebas también de una clara intención irónica o paródica, que de nuevo nos indica que el argumento no posee un sentido único ni directo, sino que debe ser traducido con distanciamiento y, a veces, hasta en sentido contrario. Un ejemplo es el último número sexual, casi en forma de epílogo, que en apariencia manifiesta 
una defensa del sexo ortodoxo, en pareja heterosexual y de sentimiento romántico, algo que desentonaría en cierta manera con anteriores afirmaciones; pero que dada la sintaxis cinematográfica de ese segmento parece más apropiado leerlo como ironía.

Quedan por tanto apuntalados los cimientos para una lectura alternativa de los textos pornográficos audiovisuales, en cualquier formato y duración, y que por su independencia frente al argumento dramático de la obra, sea éste más o menos complejo, permite extraer conclusiones más precisas acerca de sus procesos narrativos. Hemos presentado muy someramente unas herramientas para efectuar tal lectura, pero no son más que unos ejemplos de los muchos que pueden ayudarnos a interpretar estas imágenes. Es en este aspecto donde sería necesario profundizar en próximos estudios, ya que el espectro de análisis de la imagen es muy amplio y las posibilidades de perfeccionar esta lectura son, en consecuencia, inagotables.

\section{Referencias bibliográficas}

Barthes, R. (1970). Introducción al análisis estructural del relato. En R. Barthes [et al.] Análisis estructural del relato (pp. 9-43). Buenos Aires: Tiempo Contemporáneo.

Barthes, R. (1997). Sade, Fourier y Loyola. Madrid: Ediciones Cátedra.

Baudrillard, J. (1981). De la seducción. Madrid: Ediciones Cátedra.

Baudrillard, J. (1993). La transparencia del mal: Ensayo sobre los fenómenos extremos. Barcelona: Anagrama.

Chatman, S. (1990). Historia y discurso: la estructura narrativa en la novela $y$ en el cine. Madrid: Taurus.

Deleuze, G. (1984). La imagen-movimiento: Estudios sobre cine 1. Barcelona: Paidós.

Deleuze, G. y Guattari, F. (1988). Mil mesetas. Capitalismo y esquizofrenia. Valencia: Pre-Textos.

Di Lauro, A. y Rabkin, G. (1976). Dirty Movies: An Illustrated History of the Stag Film, 1915-1970. New York: Chelsea House.

Foucault, M. (1977) Historia de la sexualidad. 1. La voluntad del saber. Madrid: Siglo XXI. 
García del Castillo, A. (2011). Asalto al poder en el porno. Apropiación y empoderamiento en las narraciones postpornográficas. Revista Icono14 . 1 de Octubre de 2011, Año 9, Vol. Especial, (pp. 361-377).

Gubern, R. (1989). La imagen pornográfica y otras perversiones ópticas. Madrid: Akal.

Kleinhans, C. (2006). The Change from film to video pornography. En P. Lehman (Ed.), Pornography: film and culture (pp. 154-167). Londres: Rutgers University Press.

Escoffier, J. (2007). Scripting the sex: fantasy, narrative, and sexual scripts in pornographic films. En M. Kimmel (Ed.), The sexual self: the construction of sexual scripts (pp. 61-80). Nashville: Vanderbilt University Press.

Mulvey, L. (2001). Placer visual y cine narrativo. En B. Wallis (Ed.), Arte después de la modernidad. Madrid: Akal.

Nichols, B. (1991). Representing reality: issues and concepts in documentary. Bloomington: Indiana University Press.

Paasonen, S. (2011). Carnal resonance: Affect and online pornography. London: MIT Press.

Paasonen, S. (2011). Online Pornography: Ubiquitous and Effaced. En Consalvo, M., \& Ess, C. (Ed.). The handbook of internet studies (pp. 424-439.). Malden, MA: Wiley-Blackwell.

Preciado, B. (2001). Manifiesto contra-sexual. Madrid: Ópera Prima.

Preciado, B. (2008). Testo yonki. Madrid: Espasa Calpe.

Rouner, J. (2014). [Entrevista a Penny Antine]. What It's Really Like To Write Porn For A Living. En YourTango. Recuperado de http://www.yourtango.com/2014224426/what-its-really-like-towrite-porn-for-a-living

Schaefer, E. (2002). Gauging a Revolution: 16mm Film and the Rise of the Pornographic Feature. En Cinema Journal, 41, Number 3, Spring 2002, (pp. 3-26).

Simon, W. y Gagnon, J.H. (1986). Sexual Scripts: Permanence and Change. En Archives of Sexual Behavior, Vol. 15, No 2 (pp. 97-120).

Sontag, S. (1985). Estilos radicales. Barcelona: Muchnik Editores.

Todorov, T. (1970) Las categorías del relato literario. En R. Barthes [et al.] Análisis estructural del relato (pp. 155-192). Buenos Aires: Tiempo Contemporáneo.

van Doorn, N. (2010). Keeping it Real. User-Generated Pornography, Gender Reification, and Visual Pleasure. En Convergence: the international journal of research into new media technologies, Vol. 16, issue 4, November 2010, (pp.411-430). 
Willemen, P. (1992) Letter to John. En The Sexual Subject: a Screen reader in sexuality. (pp. 171-183). Londres: Routledge.

Williams, L. (1989). Hard core: power, pleasure, and the "frenzy of the invisible”. Berkeley: University of California Press.

Ziplow, S. (1977). The Film Maker's Guide to Pornography. New York: Drake.

\section{Referencias videográficas}

Mitchell, J. \& Mitchell, A. (Productores, Directores). (2001) Behind the Green Door [DVD] (2001). EEUU: Mitchell Brothers. 